\title{
Some investigations about the tensile strength and the desiccation process of unsaturated clay
}

\author{
H. Trabelsi ${ }^{1, \mathrm{a}}$, M. Jamei ${ }^{1}, \mathrm{H} \mathrm{Guiras}^{1}$, H. Zenzri ${ }^{1}$, E. Romero ${ }^{2}$, S. Olivella ${ }^{2}$. \\ ${ }^{1}$ Laboratoire de Génie Civil, Ecole Nationale d'Ingénieurs de Tunis, BP.37, 1002 le Belvédère Tunis, \\ Tunisie. \\ ${ }^{2}$ Department of Geotechnical Engineering and Geosciences, Universitat Politècnica de Catalunya, \\ Barcelona, Spain.
}

\begin{abstract}
The current paper presents an investigation on the tensile strength of unsaturated clay, and a discussion about the significant differences between the behaviours of compacted soils and those of the completely remoulded soils. The adapted experimental device based on the shear box for the measurement of the tensile strength is also presented. In the tensile tests, stress-strain characteristics are measured using high precision transducers and electronic data acquisition. The equipment is capable of measuring tensile strengths of soil (about $10 \mathrm{MPa}$ ). Moreover, a new model to predict cracks is presented in $3 \mathrm{D}$. This analytical model for the prediction of tensile strength, as a function of suction and porosity, is given.
\end{abstract}

\section{Introduction}

The mechanical behaviour of unsaturated soils is recently and increasingly investigated in spite of its complexity. Yet, the increasing interest in practice concerning unsaturated clayey soils subjected to hydraulic cycles (wetting and drainage) makes the investigation more interesting.

In fact, several geotechnical structures are built on unsaturated soils, and many of them are on the clayey soils (covers for the confinement of the waste, dams, embankment...). Their conception requires consideration of the climatic, hydrologic, topographic and sociologic environments. In some cases, the clayey soils are submitted to complex phenomena such as swelling and shrinkage which have an important effect on the stability of such geotechnical structures.

The research study of this effect has recently been conducted in several laboratories, where the unsaturated clayey soil behaviour requires long and complex experimental tests from microscopic to macroscopic levels. It is for example the case of shrinkage which is induced by a desiccation phenomenon. However, among the database of published results, few are the data which concern the desiccation effect on the mechanical and hydraulic properties.

For this reason, the challenge to study the tensile strength and desiccation process relationship is among the important issues in unsaturated clay behaviour. When, compacted clay is submitted to

\footnotetext{
a e-mail : houcemtr@yahoo.fr
} 
desiccation for a long period, its behaviour may be affected by the initial conditions such as dry density, water content, compaction stress ...

A number of studies were carried out in the past to characterize the mechanical behaviour of clay submitted to desiccation process with elastic assumption. Nevertheless, the behavioural features near cracking are far from being elastic, with clear irreversible strains occurring during shrinkage.

For this reason, the tensile strength may be of importance in roads' problems and airfields sub grade systems (i.e., compacted soils) subjected to important dynamic loads and where a high deformation rate occurs. The existence of tensile stresses in compacted soils is considered harmless until their intensity exceeds the tensile strength of the pavement material [1].

The tensile strength is affected by soil composition: mineralogy, grain size distribution, shape of particles, porosity...

It depends also on structure, which refers to the arrangement of particles within the soil mass: voids, cementation, and the manner in which the particles are packed or distributed ...

This paper focuses on the measurement and prediction of tensile strength of an unsaturated clayey soil undergoing a desiccation path and by considering its initial structure defined in terms of compacted or remoulded states.

To reach this goal, prepared samples are subjected to different desiccation processes. The first one corresponds to the static compaction process. The second corresponds to the drying of a remoulded specimen prepared at high initial water content (as it is often used in many laboratory investigations). The third path corresponds to a static compaction step, followed by a drying process. As it is well known, the measurement of the tensile strength of clay with controlled suction requires complex tests. In this study, direct tensile equipment was especially designed for these tests on clayey soil. This equipment is based on a modified direct shear box. The results show that the tensile strength-suction evolution depends strongly on both drying and compaction paths. These results are compared with recent published results by [2].

In parallel, the clayey soil is studied by a mercury porosimetry test to characterize the pore distribution network. The water-retention and granular size curves of the soil are also determined. The dry densities are presented as a function of water content, drying path and of Proctor compaction with a given standard energy. These curves clearly show the differences of the tensile strength evolution with suction and water content for both drying and compaction paths. The results of the laboratory tests are analyzed in the framework of unsaturated soil mechanics.

An analytical formulation to predict tensile strength as a function of suction and porosity is also proposed. Primary comparisons of numerical and experimental results have been done.

\section{Experimental investigation}

\subsection{Testing equipment for tensile strength determination}

Several methods of tensile strength testing of soils have been used in the past. Most on these tests were focused on brittle and stiff materials (compacted, dry and cement-mixed soils), which have higher tensile strengths and stiffness compared to ductile materials (soft and saturated clayey soils). In order to perform the tensile tests on compacted or remoulded clayey specimens with different initial water contents (from saturated to dry states), a tensile test device was designed based on the direct shear equipment, as shown in Figure 1.

During the tensile tests, which are conducted

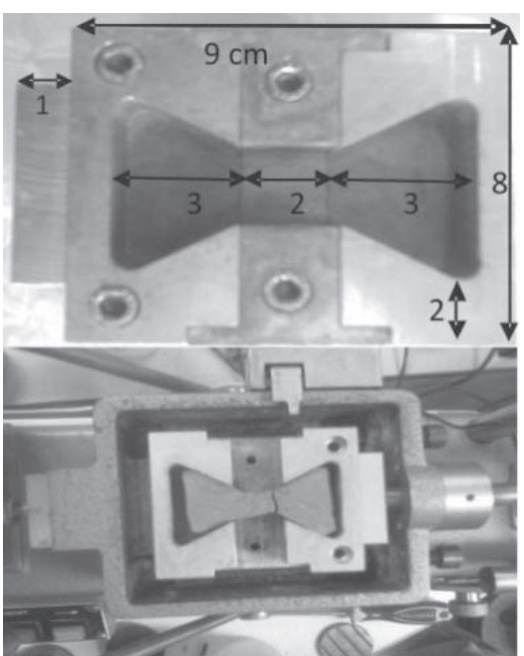

Figure 1. Tensile test device 
under a fixed displacement rate and measured using LVDT transducer, the tensile force is automatically registered. A particular convenient form of sample with a reduced centre section is adapted. The ends of the specimen under the action of axial tension force are adapted in order to transfer the tensile stress in the unconfined centre part. After the end of each tensile test, the suction is measured using different techniques: tensiometer and WP4 (for high suction $\mathrm{s}>1000 \mathrm{kPa}$ ). These tests are conducted on the undamaged part of the specimen. The water content is also measured.

\subsection{Type of soil}

The tests are performed on a clayey soil with a liquid limit of $48 \%$, a plastic index of $32 \%$, and a residual water limit $w_{r}=4.3 \%$. Its grain size distribution curve is shown in Figure 2. As it has been shown in many previous works, the relationship between the suction and degree of saturation has a very important role in the characterization of unsaturated soils. This relationship is strongly dependent on the dry density [3]. The retention curve of this clay is determined for a dry density of $\rho_{\mathrm{d}}=$ $0.95 \mathrm{Mg} / \mathrm{m}^{3}$ (Figure 3).

The results obtained from the mercury intrusion porosimetry (MIP) show the pore sizes and their distribution, which are the essential elements characterizing the structure of the soil. The pore size distribution can be related to mechanical and hydraulic properties, such as the hydraulic conductivity, the water retention characteristic, and the volumetric deformations [4].

The mercury intrusion porosimetry data of the remoulded soil displays a fabric with a dominant pore mode at around $0.2 \mu \mathrm{m}$ (figure 4 ). Pore sizes below $50 \mathrm{~nm}$ correspond to approximately $23 \%$ of the total pore volume for a dry density $1.71 \mathrm{Mg} / \mathrm{m}^{3}$.

\subsection{Specimen preparation}

In literature, it is commonly proposed that the tensile strength increases linearly with suction in the range of small values ( 0 to $1 \mathrm{MPa}$ ), and decreases for higher values. Figure 6 -b shows a different behavioural feature on drying starting from remoulded state. We discuss this observation after the description of the experimental protocol and the dry density results. 
The tensile strength is measured for the clay that is submitted to drying path. A large specimen $(30 \times 40 \mathrm{~cm})$ is dried and then a smaller piece is cut to prepare the sample in the tensile device.

For the samples prepared under a static compaction path, it can be shown that the tensile strength corresponding to higher suction values is completely different from the value obtained for remoulded samples. The modifications of the soil structure due to compaction lead to the variation of porosity and of dry density, which induces a microstructure distribution responsible for the tensile behaviour.

Figure 5 shows the evolution of the dry density with water content, for two paths: drying path of a remoulded soil sample and Proctor curve for compacted samples.

Figure 5 also shows that, depending on the initial water content, the dry density reached during shrinkage is higher than the dry

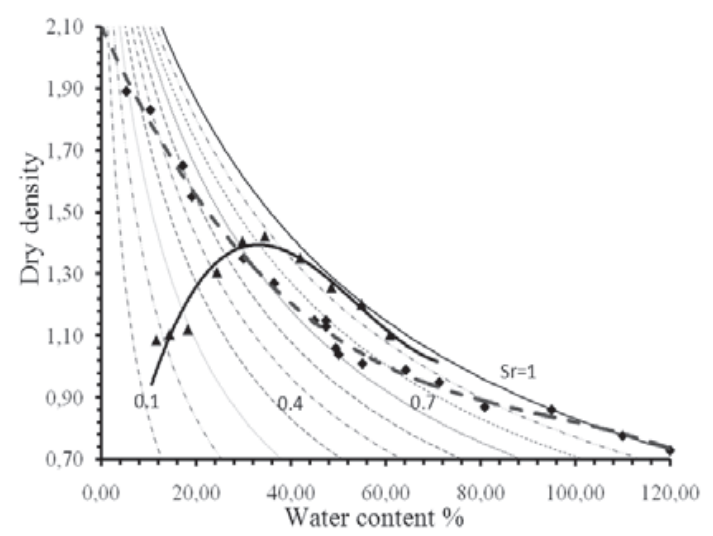

Figure 5. Proctor curve (compacted path), and dry density variation (remoulded clay) under a first drying cycle. density obtained by dry-side compaction.

\subsection{Tensile strength}

Only cohesive materials such as clay, exhibit both shear and tensile strength. Following the MohrCoulomb criterion, for many authors, the tensile strength can be captured as function of normal stress via friction angle $(\varphi)$ term and the cohesion term $(C)$. For design consideration in engineering practice, the assumed worst case scenario considers whether the saturated soil is with null or negligible tensile strength. Nevertheless, there are several phenomena which cannot be treated by the obvious simple assumption.

A typical problem is the desiccation of saturated or unsaturated clayey soils in environmental structures (cover layers of waste confinement), for shallow landslides sites, in the embankment, in agriculture field...

Three experimental series of tensile strength tests are performed. The first is for a saturated clayey soil with an initial water content $\mathrm{W}=120 \%$, which is submitted to a controlled desiccation path under a relative humidity $\mathrm{Hr}=50 \pm 5 \%$. Twenty tests are performed at different degrees of saturation. The obtained results are given in figure $6(\mathrm{a}, \mathrm{b})$. Figure 6 -a gives the tensile strength evolution against water content, following the desiccation path starting from remoulded state, as well as for the compacted states and then dried. As it can be seen (figure 6-a), the tensile strength evolution is an exponential function of water content for the desiccation path starting from remoulded states. The second series is for compacted soil with initial water content $\mathrm{W}=24 \%$. For this series of tests, the same evolution is obtained but with a higher exponential coefficient. However, in the case of compacted clay specimens at different saturation initial states, the drying path leads to the same tensile strength evolution as the dry density in the Proctor plane. Figure 6-b, shows the tensile strength against suction. This figure shows clearly that the non linear evolution, contradicts with what was published by $[2,4]$. This evolution tends to be constant for the higher suctions values.

For remoulded soils, the obtained tensile strength evolution is in agreement with the results of [2]. 

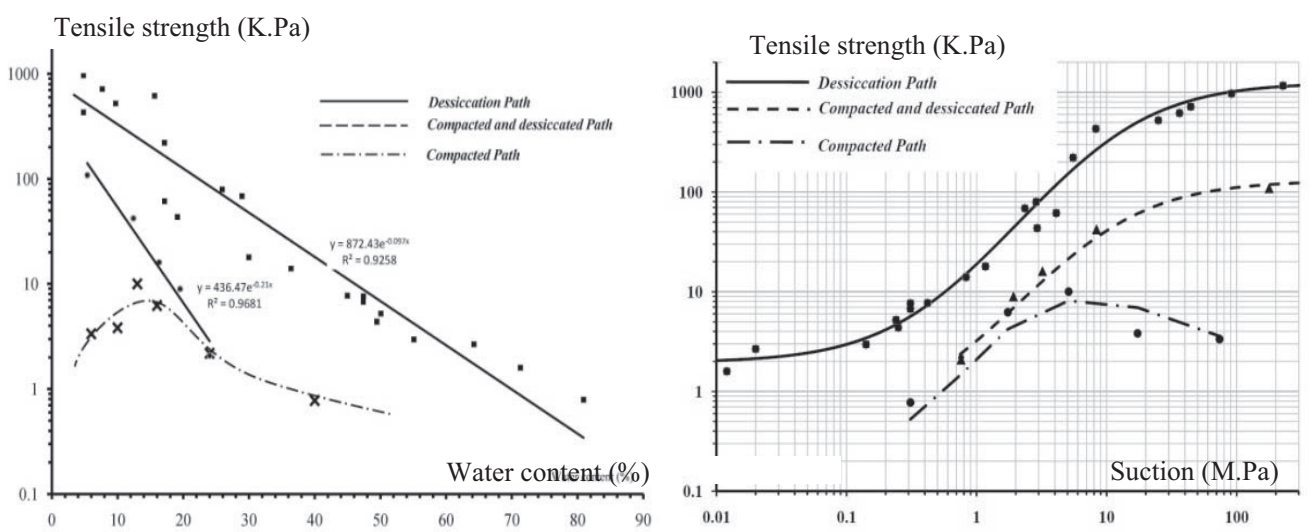

Figure $6(a, b)$. Variation of tensile strength as function of water content (a) and suction (b).

\subsection{Desiccation test.}

Figure 7 represents the evolution of cracks pattern of a circular specimen (Diameter $=40 \mathrm{~cm}$, depth= $10 \mathrm{~cm}$ ) submitted to desiccations with controlled climatic conditions. Temperature is $35^{\circ} \mathrm{C}$, and relative humidity $40 \%$.

The properties of cracks pattern are: Average crack length $\mathrm{LF}=0.075 \mathrm{~cm} / \mathrm{cm}^{2}$, Crack intensity factor $\mathrm{CIF}=32 \%$.
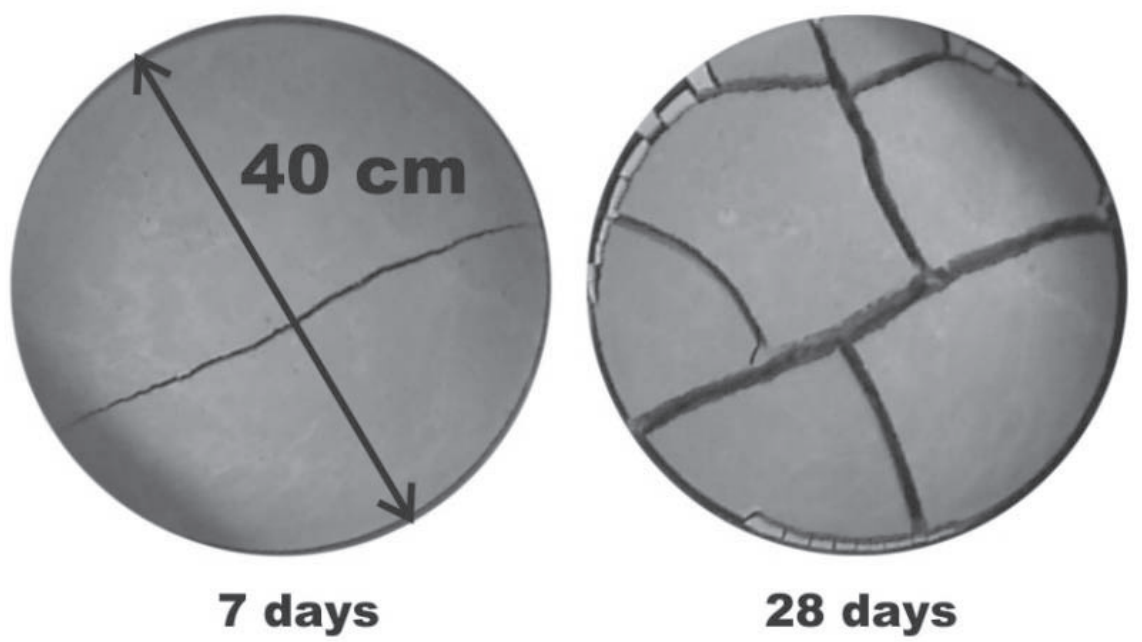

Figure 4. Evolution of Cracks pattern of clayey soil submitted to desiccations conditions.

\section{Analytical and numerical investigation}

\subsection{A proposed formulation incorporating tensile strength}

The direct tensile tests performed with the apparatus described in this paper are essentially uniaxial. However, the effect of confinement has not been investigated. We assume that the friction angle is 
independent of suction, and only the cohesion (c) can be related to the suction. We also use the experimental results to determine the evolution of cohesion with the suction $\mathrm{c}(\mathrm{s})$.

On the other hand, the tensile strength can be expressed as a function of suction. A rational relation can be calibrated for the range of suction between 0 and $250 \mathrm{MPa}$ :

$$
c=\sigma_{\text {l.Max }}\left(\frac{s+\beta_{1}}{s+\beta_{2}}\right)^{r}
$$

where $\mathrm{c}$ is the cohesion of the unsaturated soil, $\mathrm{s}$ is suction and $\mathrm{r}, \beta_{1}, \beta_{2}, \sigma_{\text {l.Max }}$ are model parameters. Form equation (1), it can be seen that the tensile strength has a minimum value when the soil is saturated and increases as the cohesion reaches a maximum tensile strength.

In addition to the suction effect, the porosity effect can also be introduced in this formulation. In fact, as porosity increases by deformation (extension), the strength decreases and the links between the particles are broken. The following relationships are then proposed:

$$
\begin{gathered}
f(\phi)=1-\left(\frac{\phi}{\phi_{0}}\right)^{n} \\
g(\phi)=\frac{(|f(\phi)|+f(\phi))}{2}
\end{gathered}
$$

where $\phi$ is the porosity of the soil, $\phi_{0}$ is reference porosity and $n$ is a material parameter. The function $g(\phi)$ is used to introduce the variation of cohesion with porosity. In this paper, cohesion is assumed as a function of porosity and suction $c(s, \phi)$, i.e. a combination of equations 1 and 3 .

$$
c(s, \phi)=\sigma_{l . M a x}\left(\frac{s+s_{1}}{s+s_{2}}\right)^{r} g(\phi)
$$

In order to use and validate the formulation and determine the required parameters, the model is implemented in CODE_BRIGHT.

\subsection{Application of analytical model in numerical application:}

\subsubsection{Boundary and initial Conditions}

In this section, we reproduce the test presented in the experimental part, the geometry of specimen (diameter $=40 \mathrm{~cm}$, depth $=10 \mathrm{~cm}$ ). The initial state of the material corresponds to a random distribution with an average porosity corresponding to the initial value and a variation with a maximum of $10 \%$. The volumetric strain is related to the temperature and suction variations, i.e. assuming a linear dependency on temperature and suction variations.

$$
\Delta \varepsilon_{v}=3 b_{s} \Delta T+3 a_{s} \Delta\left(P_{g}-P_{l}\right)
$$

A summary of the hydro-mechanical and numerical parameters used by the model is included in table 1. For all the following numerical simulations, the components of displacement vector in the nodes at the outer boundary were fixed at zero. We impose a temperature equal to $35^{\circ}$, and vapour mass to $0.034 \mathrm{Kg} / \mathrm{Kg}$ to simulate the evaporation of water in the top of specimen.

The friction between the specimen and the support is an important parameter because it is the principal parameter responsible for creating the inter stress in the specimen. This friction is 
represented in the bottom surface by a rappel forces definite linearly with displacement. In reality, this is false because friction is a linear function with velocity.

Table 1: Hydro-mechanical and numerical parameters

\begin{tabular}{|c|c|c|}
\hline \multicolumn{3}{|l|}{ ELASTICITY } \\
\hline Young Modulus (MPa) & E & 3.5 \\
\hline Variation of Young modulus with porosity (MPa) & $d E / d \phi$ & -4.5 \\
\hline Poisson's Ratio & $v$ & 0.3 \\
\hline Swelling coefficient for changes in suction $\left(\mathrm{MPa}^{-1}\right)$ & $a_{s}$ & 0.1 \\
\hline Minimum elastic modulus $\mathrm{MPa}$ & $E_{\min }$ & 0.02 \\
\hline \multicolumn{3}{|l|}{ VISCOPLASTIC AND NEW MODEL PARAMETER } \\
\hline Stress power & $m$ & 5 \\
\hline Viscosity $\left(\mathrm{s}^{-1}\right)$ & $\Gamma_{o}$ & 0.01 \\
\hline Maximum cohesion : (MPa) & $\sigma_{l}$ & 1.25 \\
\hline First specific point of suction: (MPa) & $\beta_{1}$ & 0.4 \\
\hline Second specific point of suction: (MPa) & $\beta_{2}$ & 11 \\
\hline \multicolumn{3}{|l|}{ Ductility } \\
\hline Parameter to reduce dilatancy (ranges between 0 and 1 ) & $\alpha$ & 1 \\
\hline Reference porosity & $\phi_{0}$ & 0.7 \\
\hline$M$ & $M$ & 0.85 \\
\hline
\end{tabular}

\subsection{A 3D numerical simulations}
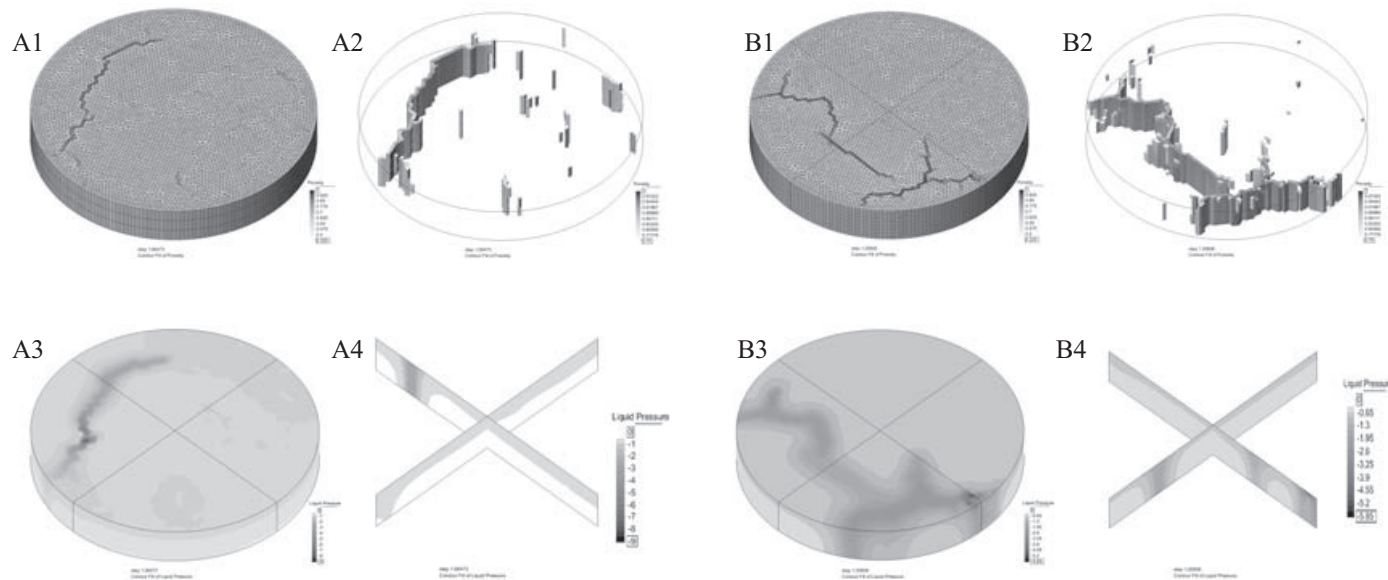

Figure 8. Evolution of Cracks pattern of clayey soil submitted to desiccations conditions. 
In order to predict the crack pattern and its evolution during desiccation, some numerical simulations have been done. The implemented formulation has given the results presented in figure 8 . It can be seen that the prediction of cracks network, after imposing a climatic condition, is in good agreement with the experimental network obtained from the experimental tests. This investigation is more developed than [5] because we have considered a coupled THM problem.

Figures 8.A represent a simulation of specimen with only three nodes in z direction "depth", and figures 8.B represent the same simulation but with 10 nodes in $\mathrm{z}$ direction. The results show the cracks pattern and the liquid pressure distribution in 3D. We note the importance of having sufficient node in the $\mathrm{z}$ direction, also we Remarque the consequence of cracks for the suction distribution inside the specimen.

\section{Conclusions}

The experimental study of the effect of desiccation process and its relation with the tensile strength evolution has been investigated. In this paper, specific attention is given to the effect of the compacted or non compacted (remoulded) clay on the both tensile strength and desiccation process. As a first theoretical prediction of these effects, a new formulation has been implemented on a FEM code to simulate crack patterns induced by desiccation. The initiation and propagation of cracks during drying was simulated via the 3D FEM code and compared with some experimental desiccation results of tests performed inside a climatic chamber.

\section{References}

1.[Humberto Blanco-Canqui ; Rattan Lal] : Aggregates, Tensile Strength of soil; Encyclopedia of Soil Science 27 March 2006.

2.[Rodríguez. R, M. Sánchez, A. Ledesma, and A. Lloret, (2007)]. Experimental and numerical analysis of desiccation of a mining waste. Can. Geotech. J. 44: 644-658.

3. [Romero E., Vaunat J., (2000)], Retention curves of deformable clays, Int. Proceedings of an international Workshop on unsaturated soils, experimental evidence and theoretical approaches in unsaturated soils, Trento, pp. 91-106.

4. [M.R. Lakshmikantha et al 2007] Discussion on "Experimental study on fracture toughness and tensile strength of a clay" [Engineering Geology 94 (2007) 64-75]

5. [Gilles Valette, Stéphanie Prévost, Laurent Lucas and Jöel Léonard, 2007].A Dynamic Model of Cracks Development Based on a 3D Discrete Shrinkage Volume Propagation. Journal compilation 2007 The Eurographics Association and Blackwell Publishing Ltd. Published by Blackwell Publishing, 9600 Garsington Road, Oxford OX4 2DQ, UK and 350 Main Street, Malden, MA 02148, USA. 